Etnográfica

Revista do Centro em Rede de Investigação em

Antropologia

vol. 15 (1) | 2011

Vol. 15 (1)

\title{
Os sentidos da segurança: ambiguidades e reduções
}

On the meaning of security: reductions and ambiguities

\section{Manuela Ivone Cunha e Susana Durão}

\section{Q OpenEdition}

Journals

\section{Edição electrónica}

URL: https://journals.openedition.org/etnografica/790

DOI: 10.4000/etnografica.790

ISSN: 2182-2891

\section{Editora}

Centro em Rede de Investigação em Antropologia

\section{Edição impressa}

Data de publição: 1 fevereiro 2011

Paginação: 53-66

ISSN: 0873-6561

\section{Refêrencia eletrónica}

Manuela Ivone Cunha e Susana Durão, "Os sentidos da segurança: ambiguidades e reduções», Etnográfica [Online], vol. 15 (1) | 2011, posto online no dia 23 outubro 2011, consultado o 12 fevereiro 2022. URL: http://journals.openedition.org/etnografica/790 ; DOI: https://doi.org/10.4000/etnografica. 790

\section{(@) $(1) \Theta$}

Etnográfica is licensed under a Creative Commons Attribution-NonCommercial 4.0 International License. 


\title{
Os sentidos da segurança: ambiguidades e reduções
}

\section{Manuela Cunha e Susana Durão}

\begin{abstract}
Segurança e insegurança são aqui pensadas através de um enfoque exploratório aberto, deliberadamente demarcado de enquadramentos recentes que têm vindo a fechar o âmbito destas noções numa só das suas dimensões, isolando-a da complexa relação que mantém com outras. Ao fazê-lo, têm-na também abstraído do conjunto de aspetos da vida social em que se encontra imersa. Retomando em toda a sua plenitude o âmbito semântico de tais noções, no qual se incluem conotações de estabilidade, previsibilidade, proteção, ou, ao invés, vulnerabilidade e precariedade, examinamos as sucessivas reduções de sentido e ambiguidades que as envolvem. Ao resgatá-las assim ao quadro redutor em que têm vindo a ser encerradas, pretendemos reconquistar a amplitude analítica necessária para acolher em tais categorias os aspetos relativos à produção de segurança ou insegurança a quaisquer níveis em que se apresentem, desde noções ideológicas e perceções culturais até relações sociais e práticas institucionais, passando pelo funcionamento do Estado e dos seus atores. É neste quadro que se apresentam, articulados, os conteúdos deste dossiê.
\end{abstract}

PALAVRAS-CHAVE: segurança, sentimento de insegurança, proteção social, vulnerabilidade social, noções de risco.

REFERINDO-SE À NOÇÃO DE "SEGURANÇA SOCIAL", FRANZ E KEEBET Benda-Beckman definiram-na, a partir de uma perspetiva antropológica, como "the dimension of social organization dealing with the provision of security not considered to be an exclusive matter of individual responsibility" (Benda-Beckman e Benda-Beckman 1994: 14). Deliberadamente ampla, uma tal definição pretendia então abrir espaço para olhar não apenas para os sistemas centralmente regulados de segurança e proteção, mas para todas as formas sociais de lidar com a insegurança, envolvessem elas a ação de organizações, grupos ou pessoas. Na mesma perspetiva, procurava-se que a segurança fosse considerada a todos os níveis em que se apresenta, isto é, não só através da prestação institucional e das políticas e ideologias nela implicadas, mas também através 
das noções culturais de risco, vulnerabilidade e cuidado que ela põe em jogo, das relações sociais que articula e das práticas por que se concretiza, sem deixar de ter ainda em conta as consequências sociais e económicas de tais práticas.

Não foi tanto o eventual propósito de abrangência por detrás desta perspetiva que quisemos transportar para este dossiê, o qual não pretende percorrer, num espírito de exaustividade equivalente, as várias facetas da segurança. É antes um espírito de abertura semelhante, pois que recusamos também fechar à partida o campo da segurança numa só das suas dimensões. Que essa abertura possa tornar um tal campo pouco operatório por efeito de uma diluição excessiva é um risco que aqui não nos preocupa. O que pretendemos é, precisamente, reconquistar a amplitude necessária para manter interrogável uma noção cujos usos nas últimas décadas lhe têm vindo, ao invés, a estreitar os âmbitos semânticos através de reduções sucessivas, a sedimentá-la nesses significados empobrecidos - sem que essa redução seja neutra do ponto de vista político. Tão-pouco são neutras, tanto nos efeitos como na instabilidade dos seus contornos, as ambiguidades e derivas de noções que têm vindo a proliferar no interior desses âmbitos, como se especificará adiante.

É aqui nossa intenção sobretudo assinalar essas ambiguidades e reduções de sentido tal como elas têm emergido em terrenos e conjunturas contemporâneos, assim como seguir os cruzamentos mais ou menos imprevistos que a sua análise convoca, fazendo-a enveredar descomplexadamente por uma variedade de outros tópicos temáticos, mesmo aqueles cuja abordagem não surge habitualmente associada à questão da segurança. Por esta razão prescindimos deliberadamente de nos posicionarmos à partida por relação a um qualquer estado da arte na matéria, e ainda menos por relação a uma qualquer "região demarcada" de estudos de segurança, com limites predefinidos.

Quanto aos estreitamentos de sentido em que tem incorrido a noção de segurança, as inseguranças da vida social contra as quais se procura assegurar proteção veem-se paulatinamente reduzidas, em sucessivas redefinições e em especial no que toca ao papel do Estado nessa proteção, a uma estrita dimensão criminal, sendo esta por sua vez reduzida especificamente à dimensão de delinquência de rua. E é a este nível que a segurança passa também a surgir em modo cénico, espetacularizado, no espaço público, sendo agora sobretudo por esta via que o Estado procura demonstrar uma capacidade de intervenção que perdeu, ou da qual foi abdicando, na esfera económica e social: "governar através do crime" (Simon 2007) é uma tendência que se foi afirmando a partir dos anos 1970 nos Estados-providência, ainda que em graus variáveis. ${ }^{1}$ A "mise-en-scène da segurança", segundo uma expressão utilizada a este propósito por Loïc Wacquant (2009), desenrola-se sobretudo em determinados espaços sociais e urbanos - a "rua" dos bairros pobres, os quais são 
regularmente objeto de operações de segurança e demonstrações de força com aparato militar que alcançam, amiúde, ampla projeção mediática, assegurada pela presença de câmaras de televisão (ver Cunha no prelo).

Luís Fernandes e Ximene Rêgo referem-se aqui, também eles, à dimensão mediática como constitutiva da especificidade das formas contemporâneas do sentimento de insegurança, algo que Stanley Cohen (2002 [1972]) implicara nalguns esquemas básicos da "ampliação da desviância” e da fabricação de "pânicos morais", os quais se repetem sucessivamente. Mas estes autores veem-na também como constitutiva da tendência para a reposição simbólica do papel do Estado por esta via, isto é, pela reafirmação de um poder que procura acima de tudo afirmar-se enquanto garante da ordem. Uma e outra coisa traduzir-se-iam, de resto, em sequências de eventos compondo uma mesma estrutura, reproduzida de episódio em episódio com uma sucessão previsível nos media.

A representação pública da segurança coletiva passa, em todo o caso, cada vez menos por uma ideia de estabilidade e previsibilidade ligada a níveis mínimos de bem-estar e proteção contra as incertezas, para assentar numa noção de risco que sofreu, também ela, uma redução de sentido. Como referiu Pat Carlen, a tradução de "risco enquanto perigo" triunfou sobre a de "risco enquanto privação social" (2007: 1013). E no entanto, não é por acaso que a insegurança em relação ao crime se cristalizou como problema social em vários contextos euro-americanos, sobretudo a partir da segunda metade da década de 1970, sem que se tivesse registado até então uma expansão da delinquência predatória ou violenta (Robert 1999). Há muito que é conhecida a relativa autonomia do sentimento de insegurança, isto é, ele não surge como uma reação mecânica simples à pressão da delinquência. A complexa relação entre insegurança e crime tem, antes de mais, de começar por ser colocada no contexto das transformações que começam a afirmar-se nesse período, especialmente a mutação do mercado de trabalho, traduzida na crise do pleno emprego e do estatuto salarial estável, e a destabilização do acesso a pilares do Estado social, como sejam a proteção social e os serviços públicos. É também neste contexto, aliás, que passam em última instância a articular-se numa mesma lógica dois setores aparentemente distintos do mercado de segurança, doravante em franca expansão: a atividade seguradora e uma variedade de prestadores de segurança (Agra 2002). O sentimento de insegurança encontrará nesta conjuntura terreno fértil, sendo assim que ele prospera sobretudo, não tanto entre os que se encontram mais imediata e diretamente ameaçados pelo crime predatório, mas entre aqueles que se veem a si próprios em situação de maior incerteza e vulnerabilidade social, e são mais sensíveis à ausência de uma ação pública eficaz nos vários âmbitos da segurança (Robert 1999).

Nada do que precede pretende sugerir que o sentimento de insegurança é um medo sem objeto ou sem conexão alguma com as realidades do risco-perigo. Mas, como sustenta Jock Young (1999: 74-78), além de a perceção do crime 
e do risco de vitimização formarem um continuum com a perceção de outros problemas sociais e com outras inquietações urbanas, varia também segundo as categorias sociais (de género, de idade, por exemplo) e adquire em cada uma um significado específico. Por isso, dado que perceções e representações são desde logo inerentes ao comportamento humano, não teria sequer sentido proceder a um cotejo direto, não mediado, entre o risco real - estatisticamente calculado - e o sentimento de insegurança. Tal confronto não seria mais do que uma abstração positivista ingénua. Procurar uma correlação positiva ou negativa entre ambos para averiguar até que ponto o sentimento de insegurança é ou não desproporcionado não passaria, por conseguinte, de um exercício no vazio, descolado das dinâmicas da realidade social. Seria, em vez disso, mais profícuo tentar captar o sentido que adquire dentro das diversas categorias sociais (Young 1999: 74). ${ }^{2}$ Além disso, alega ainda Young, haveria que levar em conta o aumento da expetativa ou do nível da exigência social de segurança na modernidade tardia. ${ }^{3}$

Seja como for, talvez uma das ambiguidades inerentes à produção histórica da associação entre crime e medo decorra dessa espécie de vida autónoma que conquistaram as noções de segurança e insegurança "subjetivas" (como algo que difere da segurança e insegurança "objetivas"). Parte-se do princípio de que há uma ordem de aspetos invisíveis, não quantificáveis mas poderosamente presentes e aos quais genericamente se chama "fatores subjetivos". Toda essa subjetividade ganha contornos de entidade nas políticas públicas. Mas o medo não é pré-discursivo. É produzido como categoria através das atividades de agências, poderes e saberes que lhe moldam o conteúdo através da forma como trabalham, refinam, testam e reportam esse medo, num processo que Lee (2007) designou como retorno permanente do medo do crime (the fear of crime feedback loop). A um nível mais genérico, esta construção não deixa de ter ressonâncias com várias outras produções discursivas, tanto à escala local como à escala global e transnacional. O medo reconfigura-se no formato fluido das vulnerabilidades dos Estados, mas também dos seres humanos e dos corpos, encontrando-se a cada momento várias figurações para o "desconhecido". Este pode ser o "marginal", violento e perigoso (Athens 1992), o "popular

2 Para um confronto de perspetivas sobre esta questão em Portugal, ver Eduardo V. Ferreira (1998) e, a seu propósito, Pedro M. Ferreira (2001), além do trabalho de Carla Machado (2004).

3 "To hinge the question on whether ["risk rates"] have actually risen and whether they are phrased in an alarmist fashion fundamentally misses the point. In some instances they have risen, in many cases they are exagerated, but what is important is that the base line of evaluation has increased as has the demand for a higher quality of life [...]. It is not so much that modernity has failed to keep its promise to provide a risk-free society as that late modernity has taken seriously this promise, has demanded more and realized the greater difficulty of its accomplishment" (Young 1999: 78; itálico no original). 
demonizado" (Cohen 2002 [1972]), o terrorista, um migrante, o pedófilo ou as conexões atemorizadoras que a tecnologia proporciona. ${ }^{4}$

Referindo-se precisamente ao facto de a expressão do sentimento de insegurança estar rodeada de ambiguidades, Luís Fernandes e Ximene Rêgo fazem notar que ele é afinal coerente com as funções que desempenha na economia das relações sociais. Pode cristalizar-se no medo do crime, pode crescer em torno dos signos espaciais e sociais de desordem, mas transporta-nos para lá deles: "interroga a direção que está a tomar todo o conjunto social". Com base em investigação etnográfica em terrenos urbanos do Porto, identificam os ingredientes do rumor insecurizante e analisam o modo como se opera uma rotação histórica das formas e lugares dos medos públicos, focalizados primeiro na cidade como espaço predatório e cristalizados depois em novas franjas de marginalidade, mas agora transmutando-se discursivamente em "sentimentos de insegurança" - em linha com a nova terminologia que os erige em objeto científico e questão de especialistas.

Tendo por referência terrenos urbanos no Rio de Janeiro, a análise aqui proposta por Luiz Machado da Silva cruza-se com a de Luís Fernandes e Ximene Rêgo ao incidir sobre a "província de significado" de um ingrediente-chave na constituição do sentimento de insegurança e das formas de segurança que lhe procuram dar resposta: a violência urbana. Trata-se de uma categoria discursiva que, segundo o autor, articula, de acordo com uma gramática própria, uma série de enunciados relativos a um leque de práticas transgressivas bastante díspares, de simples incivilidades à violência física, mas sendo-lhes comum o facto de afetarem a continuidade das rotinas quotidianas.

Porém, o protagonismo conquistado por esta categoria discursiva na esfera pública teria uma série de efeitos afuniladores que inviabilizariam à partida a procura de soluções de fundo, passando por uma recomposição da sociabilidade urbana num horizonte temporal mais dilatado, e condenando à futilidade programas de reforma institucional da polícia. Tal categoria reduziria a tematização do controlo social ao simples risco de quebra destas rotinas, e deixaria o debate inteiramente cativo dos aspetos mais imediatos das questões de ordem pública, concebida também ela de forma limitada à componente repressiva.

4 David Altheide (2006) exemplificou como se produz a "política de medo" num estudo que incidiu sobre o uso público de conceitos nos 18 meses que antecederam e se sucederam, em igual número, aos ataques de 11 de setembro de 2001, tendo constatado como se associaram, de modo dramático, as ideias de terrorismo, medo e vitimização. Zbigniew Brzezinski (2007), que acompanhou de perto o funcionamento da esfera política enquanto conselheiro do presidente Jimmy Carter nos EUA, referiu-se, à semelhança de vários autores, ao facto de o uso da expressão "guerra ao terror" ter sido criado para intensificar a cultura do medo através da intensificação de emoções suscetíveis de atrair apoio para políticas de controlo específicas. Mas tal metáfora está longe de ser uma novidade. Esta foi precedida pela "guerra ao crime", a "guerra às drogas", e foi usada de modo também punitivo e discriminatório em éticas da guerra na área da medicina (Sontag 1988). 
$\mathrm{Na}$ perspetiva do autor, mais do que a regulação das relações entre pessoas e grupos, o "reducionismo essencial da linguagem da violência urbana" não deixaria senão lugar a um apelo ao bloqueio dessas relações através da repressão, evitação e afastamento. Tal passaria, nesta lógica, tão-só pelo aumento da eficácia da repressão policial por via de um aperfeiçoamento técnico e de uma maior margem de ação e arbítrio.

Referimos acima o triunfo da tradução de "risco enquanto perigo" sobre a de "risco enquanto privação social". Saberes especializados foram coconstrutores desta inflexão, a qual tende, em consonância, a desembocar menos numa intervenção transformadora junto de populações "em risco" - horizonte que regia o ethos modernista da maior parte do século passado - do que numa proteção face a populações que "representam um risco". ${ }^{5}$ Tal inflexão implicou, em consequência, respostas de cariz essencialmente defensivo e de prevenção situacional, apostando no apuramento de dispositivos de segurança, em técnicas de evitamento da vitimização e na diminuição da vulnerabilidade de pessoas, coisas, edifícios e áreas a incidentes criminais, em aumentar os obstáculos e os riscos para os delinquentes ou em reduzir concreta e localizadamente as oportunidades para delinquir. ${ }^{6}$ Ela acompanha-se, por outro lado, de uma proliferação de prestadores de novos serviços neste âmbito, como vigilantes de empresas de segurança subcontratadas, agentes e neovigilantes de vários tipos contratados por coletividades locais, empresas de transportes públicos e centros comerciais para cogerirem espaços coletivos. Todos estes novos atores compõem aquilo que foi já designado como neoproletariado da segurança (Robert 1999) - aliás também ele afetado por uma precariedade genérica pautada pela insegurança social.

Do apuramento das técnicas de segurança participa a videovigilância, em plena expansão (ver Frois 2008). Porém, a sofisticação da vigilância tecnológica e a expansão da parafernália de monitorização não se pautam propriamente por uma lógica disciplinar, a não ser nas classificações em que por vezes se apoiam. Estas, todavia, estão agora mais ao serviço da constituição de perfis de perigosidade do que de propósitos ortopédicos. A vigilância encontra-se aqui esvaziada de qualquer essência pan-ótica, destinando-se acima de tudo a maximizar a segurança. ${ }^{7}$ Dito de outro modo, se a lógica disciplinar partia da distribuição

5 Esta tendência pode ser associada à viragem atuarial ou estocástica a que se refere Jonathan Simon (1988).

6 Este é o denominador comum de várias teorias criminológicas, conhecidas pelas designações de "escolha racional" (Cornish e Clarke 1986), "controlo situacional", "atividades de rotina" (Clarke e Felson 1993) e "espaço defensável” (Coleman 1985).

7 Também nas prisões contemporâneas os signos aparentes da sofisticação da vigilância tecnológica estão longe de corresponder, ao contrário do que alguns autores sugerem (e.g. Sparks 1995), ao que seria uma reedição do modelo pan-ótico na sua expressão mais acabada. Como nota Santoro (2005), se se multiplicam instituições "pan-óticas" de um ponto de vista tecnológico, assentes [continua] 
dos comportamentos em torno de uma norma, e "o poder operava no sentido de colmatar as brechas, de estreitar as margens de desvio, de orientar os indivíduos para a uniformidade" (Simon 1988: 773), numa lógica estocástica o objetivo é, em vez disso, "lidar da maneira mais eficiente possível com uma população tal como ela se apresenta, sem procurar mudá-la” (1988: 773). ${ }^{8}$

Foi Foucault $(1997,2004)$ quem primeiro identificou uma mutação histórica (glosada depois por Gilles Deleuze 1990) consistindo na passagem de uma sociedade "disciplinar" para uma sociedade de "segurança". ${ }^{9} \mathrm{O}$ dispositivo de segurança, caraterístico das formas dominantes da penalidade contemporânea, teria vindo organizar a prevenção, calculando probabilidades, riscos e custos. Enquanto os mecanismos da lei e da disciplina procuravam repercutir da maneira mais homogénea e exaustiva possível a vontade de um soberano sobre os seus súbditos, os da segurança seguiriam a população nas suas dinâmicas próprias, sendo a esse nível que a ação dos governantes deveria surgir como "necessária e suficiente" ao equilíbrio global (Foucault 2004: 68). É de resto por isso mesmo que Foucault diz ser estranha ao dispositivo da segurança a ideia do pan-ótico, pois que este tem necessariamente um centro de onde irradia a vigilância pela qual um "soberano" exerce o maior poder possível sobre os indivíduos.

Mas se é certo que se passou a uma sociedade de segurança, esta não conota agora apenas a dimensão reguladora apontada por Foucault e em função da qual o conceito de governo foi deixando progressivamente de ser usado por este autor na aceção de autoridade pública, ou de exercício de soberania, para passar a reportar-se sobretudo às "técnicas específicas de gestão das populações” (Senellart 2004: 396), evoluindo depois ainda para a noção de "governabilidade". Na verdade, não se trata agora só de regular na retaguarda processos biossociológicos de populações, mas, como referimos acima, de afirmar simbólica e ostensivamente o poder e a autoridade do Estado num momento em que o papel deste surge como cada vez mais residual noutras áreas. À crise do Estado-providência, que é paralela à crise das disciplinas, sucede um Estado

na ideia de vigilância contínua, estas não podiam estar mais afastadas da essência do projeto benthamiano, em que a monitorização permanente estava ao serviço do propósito de fabricar corpos dóceis. O pan-ótico tecnológico não se rege por nenhum fim disciplinar, visando apenas garantir a segurança máxima.

8 É de ressalvar contudo que, do mesmo modo que o programa modernista tanto teve aplicações benignas como desumanizadoras e intrusivas (Garland 1995: 188-189), também a racionalidade estocástica não tem forçosamente uma tradução política unívoca. Dela decorrem, por exemplo, tanto políticas antiassistencialistas quanto políticas que dificilmente se podem considerar conservadoras, como as políticas de redução de riscos na área da toxicodependência (troca de seringas, salas de injeção assistida), isto é, programas cuja finalidade não é suprimir a dependência, nem eliminar o "desvio", mas lidar com eles e geri-los de forma a serem o menos danosos possível.

9 Em La Volonté de Savoir, Foucault (1976) chamar-lhe-á uma sociedade de “controlos reguladores". Retoma-se aqui um ponto desenvolvido em Cunha (2008). 
que, perante os eleitores, se quer pujante na oferta da segurança e ordem pública, à medida que o "direito à segurança social" se vem transmutando em "direito à segurança" tout court.

Este direito à segurança que o Estado procura implementar pode passar também por novas formas de controlo, avaliação e monitorização assentes em projetos técnico-genéticos, como sejam as bases de dados de perfis de ADN, cujo processo de criação recente em Portugal é aqui analisado por Helena Machado. Apresentando-se como uma forma de vigilância baseada no conhecimento tecnocientífico da individualidade biológica, a biossegurança surge envolta numa aura de verdade e infalibilidade que potencia as promessas de segurança e tranquilidade coletivas através de garantias de eficácia na identificação, prevenção e dissuasão do crime. No entanto, o cientismo que envolve as representações públicas desta tecnologia vem dar novo fôlego a retóricas que tornam o seu uso impermeável à participação cívica no seu escrutínio, reservando-o a uma classe jurídico-científica de peritos e divorciando-a assim da sociedade que pretende servir.

Tal não impede, todavia, a coexistência destas respostas defensivas mais ou menos sofisticadas com estratégias interventivas de cariz repressivo direcionadas para territórios específicos, ${ }^{10}$ como as apontadas aqui por Luiz Antonio Machado da Silva. Focando as práticas e atitudes dos agentes de uma esquadra da PSP de Lisboa, Susana Durão refere igualmente neste dossiê uma "visão cartográfica" do policiamento e da cidade, a qual diferencia os bairros de "classe média", os "bairros da droga" e os "bairros pobres" ou "populares" e tende a reproduzir no policiamento desigualdades sociais manifestas no espaço urbano, intensificando a atividade penalizadora nuns e reservando a atividade de manutenção da ordem quotidiana a outros. Assim, políticas de "tolerância zero" tornam-se mais frequentes e focam-se mais em bairros pobres, envolvendo a identificação e a detenção de indivíduos com níveis baixos de desviância e de criminalidade, especialmente nos domínios públicos (Herbert 2001).

Mas o esboço espacial desta dualização de estilos não deixa de refletir o modo como são negociadas no quotidiano algumas das ambivalências e das ambiguidades que atravessam o mandato policial, geradas em torno de uma série de injunções que se apresentam de modo dual, como prevenção/repressão, apoio/controlo, serviço/segurança e ordem, policiamento de proximidade/controlo do crime. Mais do que isso, a gestão de tais injunções pode ver-se condicionada por contradições fundamentais. Se a maior parte da atividade da polícia passa por resolver "questões de manutenção e gestão de ordens quotidianas", a faceta mais valorizada na representação da profissão e na definição da própria identidade profissional é a operacionalidade na área do crime, a qual não

10 Ver, a propósito desta coexistência, Young (1999), assim como Cunha (2002) para a sua problematização. 
corresponde, porém, senão a uma dimensão bastante reduzida das práticas que constituem o grosso do trabalho policial. Estas práticas são, assim, objeto como que de uma invisibilização pública e institucional. Além disso, considerando apenas essa parcela restrita referente à área do crime, é possível entrever nesta investigação como os chamados bairros problemáticos têm vindo a constituir-se como um lugar privilegiado de construção e performance dessa mesma identidade profissional. Tal incorpora assim mecanismos de reconhecimento público que assentam menos na vigilância dissuasora, na mediação social e numa negociação dos diferendos próxima dos problemas locais - tarefas que definem na essência o policiamento de proximidade -, do que no aforismo segundo o qual "é o grande criminoso [real ou pressuposto] que faz o grande polícia".

Da mesma forma que se produziu uma rotação discursiva do medo à cidade para o sentimento de insegurança, também se deu uma migração da noção de "ordem" para a de "segurança", embora ela traduza menos uma diferença de modelos do que de conotações históricas e políticas. Se a noção de segurança se apresenta com uma face relativamente neutra, em Portugal como nos contextos brasileiros abordados por Machado da Silva, a noção de "manutenção da ordem" evoca sobretudo um controlo extrínseco de cariz repressivo, contrariamente a conotações anglo-saxónicas em que ela passa antes de mais por uma gestão de equilíbrios coletivos e por mecanismos locais de autocontrolo. E é, de resto, precisamente uma tal orientação que se tem tentado incorporar no funcionamento das polícias em vários países.

Mas nem por isso esta difusão, que marcou a evolução recente dos modelos de ação policial e as novas conceções acerca do relacionamento entre a polícia e a população, é menos isenta de derivas e ambiguidades. ${ }^{11}$ Neste âmbito proliferam as designações - correspondendo a uma variedade de abordagens ou a diferentes raízes nacionais -, que vão desde a de "polícia de proximidade" e "polícia de orientação comunitária", à de "polícia orientada para a resolução de problemas" (Goldstein 1990; Brodeur 2001; Normandeau 1998) e "polícia de qualidade de vida”. Esta última designação é talvez a que evoca de maneira paradigmática os sentidos dúbios que estas expressões são suscetíveis de assumir, na medida em que sob ela se amalgamam estratégias distintas, ainda que conexas, de policiamento e manutenção da ordem pública, e em que acabou ainda por acolher a ideia da "tolerância zero", da qual se veio a tornar um eufemismo (Silverman e O'Connell 1998; Wacquant 2009). Mas ela não é senão um exemplo extremo do tipo de derivas que outras têm sofrido. Para referir apenas o que é talvez a designação mais genérica - e de uso mais generalizado -, a etiqueta "polícia de proximidade" tem sido objeto das apropriações sociais e políticas mais variadas, ao ponto de, por vezes, o sentido atual contrastar radicalmente com o seu espírito inicial. 
Algumas dessas derivas práticas ou apropriações espúrias mostram como se foram produzindo deslizes sucessivos nas ideias que o modelo da polícia de proximidade procurara promover e que resultaram no seu desvirtuamento nalguns contextos contemporâneos. Por exemplo, da ideia de que todas as funções que a polícia assume, mesmo a resolução dos problemas mais triviais, são componentes igualmente legítimas ou dignas do trabalho policial, pode deslizar-se para a ideia de que todos os problemas são graves por igual e que, por isso, se deve lidar com eles com igual severidade (e o resultado é a repressão desproporcionada das pequenas desordens, como tem sucedido com a implementação da "teoria" das janelas partidas); da ideia de uma maior ligação à comunidade, em que a comunidade é vista como sujeito da sua segurança, pode deslizar-se para uma focalização em certas comunidades, em que estas figuram como objeto de uma repressão acrescida (é o caso de alguns bairros, em que a ideia de proximidade da polícia adquiriu todo um outro sentido); de uma ideia de pró-atividade que consiste em intervir antes que os problemas deflagrem, pode deslizar-se para a ideia de que se trata apenas de intervir ex post naquilo que, tendo ocorrido, não é denunciado - neste caso, desliza-se para uma ideia de seleção de alvos que frequentemente cria condições de intensificação da repressão e que é muitas vezes um fator de multiplicação de incidentes (ou seja, em vez de ser uma modalidade da prevenção, a pró-atividade acaba por figurar como uma nova modalidade da repressão) -; por fim, do incentivo à participação da população na sua própria vigilância e segurança, há o risco de se deslizar para a demissão do Estado nesta incumbência.

Do que precede, o par legalidade/ilegalidade parece ainda assim alinhar-se de maneira simples pelo par segurança/insegurança, sendo a segurança e a legalidade asseguradas pelo Estado: este figura como garante de ambas através dos seus agentes que, na linha da frente, medeiam entre a lei e a rua. No entanto, a antropologia tem desafiado concetualizações do Estado como uma entidade orgânica una e singular, agindo de maneira consistente e indiferenciada, tendendo em vez disso a encará-lo como uma teia diversificada de instituições, procedimentos e atores que coexistem de maneira complexa em múltiplos patamares, locais e nacionais (Ferguson e Gupta 2002; Migdal 1994; Mitchell 1991; Scott 1998; Thelen e Read 2007).

Os polícias, tal como os fiscais municipais e muitos outros agentes locais do Estado em contacto direto com a população - e que Lipsky (1980) designou como "burocratas de rua" (street-level bureaucrats) -, são de facto rostos do Estado (Durão 2008). Mas, como mostram os textos de José Carlos G. Aguiar e Fernando Rabossi, é simplista opor atores estatais e atores ilegais como blocos separados, aos quais corresponderiam diferentes valores e modalidades distintas de ação. A etnografia de José Carlos G. Aguiar sobre a venda a retalho de contrafações no mercado de San Juan de Dios em Guadalajara (México) expõe a rede complexa de trocas e lealdades ambíguas em que ambos se encontram 
relacionados, contexto comum esse que não pode deixar de ser tido em conta numa economia política da corrupção.

Mais uma vez, porém, não é só de legalidade e ilegalidade que se trata, mas também da segurança ou insegurança que lhes surgem associadas. Esta associação não é linear, mas contraditória e ambígua quando os próprios atores estatais são um fator de insegurança na gestão das ilegalidades. No caso estudado por José Carlos G. Aguiar, os arranjos que as toleram são voláteis, imprevisíveis e geradores de mais risco. No contexto analisado por Fernando Rabossi, é o funcionamento das diferentes instâncias da lei e do Estado que, em lugar de estabilizar a "rua", a instabilizam.

A "rua", quer como espaço urbano quer como categoria discursiva, ${ }^{12}$ é porventura o cenário contemporâneo onde mais se projeta o "sentimento de insegurança”. Mas, mesmo considerado a este nível, o sentimento de insegurança não se configura forçosamente nos moldes com que tal noção circula no senso comum e na esfera pública, moldes esses coincidentes, de resto, com a perspetiva estreita que o reduz ao medo do crime predatório e da qual pretendemos demarcar-nos neste dossiê. O texto de Fernando Rabossi sobre o comércio de rua em Ciudad del Este, no Paraguai, demonstra bem, mais uma vez, a necessidade de resgatar a noção de insegurança ao quadro redutor em que tem vindo a ser encerrada. Para mais, leva-nos a infletir a perspetiva sobre o modo como "a rua" é suscetível de constituir-se como cenário de insegurança, abordando-a aqui não como espaço de circulação, mas de trabalho. Deste ponto de vista, a rua surge também como um mundo inseguro e imprevisível. Mas insegurança significa aqui instabilidade e precariedade. Não tanto a instabilidade e precariedade inerentes às caraterísticas da atividade em si (vender na rua, ao invés de numa loja, implica produzir diariamente o espaço de trabalho através da montagem e desmontagem quotidiana de estruturas ou da circulação constante ao encontro de compradores), mas sim aquelas que envolvem as condições de apropriação da rua como meio de sobrevivência. Acontece, porém, que a permanente falta de segurança e estabilidade tem origem nas dinâmicas legais e políticas da regulação do acesso à rua. São as indefinições, contradições e inconsistências da lei e dos regulamentos, bem como a incoerência na sua implementação por parte dos vários agentes oficiais - a qual inclui o tratamento diferenciado das transgressões -, que reproduzem e amplificam essa precariedade, além de serem elas próprias geradoras de novos ilegalismos.

Assim, a questão da segurança reconduz-nos forçosamente a considerar não só a gestão da ilegalidade, mas também a gestão da própria legalidade. E, nesse movimento, não deixamos de ser remetidos para a intervenção estruturadora da desigualdade.

12 Ver, a propósito das ambiguidades que rodeiam também esta categoria, Wacquant (2002). 


\section{BIBLIOGRAFIA}

AGRA, Cândido, 2002, "Prefácio", em Philippe Robert, O Cidadão, o Crime e o Estado. Lisboa, Editorial Notícias, 7-16.

ALTHEIDE, David L., 2006, "Terrorism and the politics of fear", Cultural Studies, Cultural Methodologies, 6 (4): 415-439.

ATHENS, Lonnie H., 1992, The Creation of Dangerous Violent Criminals. S/1, University of Illinois Press.

BENDA-BECKMAN, Franz von, e Keebet von BENDA-BECKMAN, 1994, "Introduction: coping with insecurity: an 'underall' perspective on social security in the Third World", Focaal: European Journal of Anthropology, 22/23: 7-34.

BRODEUR, J.P., 2001, Comparisons in Policing: An International Perspective. Aldershot, Ashgate.

BRZEZINSKI, Zbigniew, 2007, “Terrorized by 'war on terror': how a three-word mantra has undermined America”, The Washington Post, 25 de março.

CARLEN, Pat, 2007, "A reclusão de mulheres e a indústria de reintegração", Análise Social, XLII (185): 1005-1019.

CLARKE, Ron, e Marcus FELSON (orgs.), 1993, Routine Activity and Rational Choice. New Brunswick, Transaction.

COHEN, Stanley, 2002 [1972], Folk Devils and Moral Panics. Nova Iorque, Routledge.

COLEMAN, Alice, 1985, Utopia on Trial. Londres, Hilary Shipman.

CORNISH, Derek, e Ron CLARKE, 1986, The Reasoning Criminal: Rational Choice Perspectives on Offending. Nova Iorque, Springer-Verlag.

CUNHA, Manuela P. da, 2002, Entre o Bairro e a Prisão: Tráfico e Trajectos. Lisboa, Fim de Século.

— , 2008, "Disciplina, controlo, segurança: no rasto contemporâneo de Foucault", em Catarina Frois (org.), A Sociedade Vigilante: Ensaios sobre Privacidade, Identificação e Vigilância. Lisboa, Imprensa de Ciências Sociais, 67-81.

— no prelo, "Droga, transformaciones de la represión y ambiguidades de la seguridad: la construcción de objetivos en el control de la criminalidad”, em Dario Malventi (org.), Crímenes de Paz. Sevilha, UNIA.

DELEUZE, Gilles, 1990, "Post-scriptum sur les sociétés de contrôle”, em Pourparlers: 1972 -1990. Paris, Minuit, 240-247.

DURÃO, Susana, 2008, Patrulha e Proximidade: Uma Etnografia da Polícia em Lisboa. Coimbra e São Paulo, Almedina.

FERGUSON, James, e Akhil GUPTA, 2002, "Spatializing states: toward an ethnography of neoliberal governmentality”, American Ethnologist, 29 (2): 981 -1002.

FERREIRA, Eduardo Viegas, 1998, Crime e Insegurança em Portugal: Padrões e Tendências, 1985-1996. Oeiras, Celta Editora.

FERrEIRA, Pedro Moura, 2001, recensão de E. V. Ferreira, Crime e Insegurança em Portugal: Padrões e Tendências, 1985-1996, Oeiras, Celta Editora, 1998, Análise Social, XXXV (156): 833-838.

FOUCAUlT, Michel, 1976, La Volonté de Savoir. Paris, Gallimard.

__, 1997, Il Faut Défendre la Société: Cours au Collège de France, 1975-1976. Paris, Gallimard.

—, 2004, Sécurité, Territoire, Population: Cours au Collège de France, 1977-1978. Paris, Seuil/Gallimard. 
FROIS, Catarina (org.), 2008, A Sociedade Vigilante: Ensaios sobre Privacidade, Identificação e Vigilância. Lisboa, Imprensa de Ciências Sociais.

GARLAND, David, 1995, "Penal modernism and postmodernism", em T. Blomberg e S. Cohen (orgs.), Punishment and Social Control: Essays in Honor of Sheldom Messinger. Nova Iorque, Aldine de Gruyter, 181-209.

GOldstein, H., 1990, Problem Oriented Policing. Nova Iorque, McGraw Hill.

HERBERT, Stephen, 2001, "Policing the contemporary city: fixing broken windows or shoring up neo-liberalism?”, Theoretical Criminology, 5 (4): 445-466.

LEE, Murry, 2007, Inventing Fear of Crime: Criminology and the Politics of Anxiety. Cullompton, UK, Willian Publishing.

LIPSKY, Michael, 1980, Street-Level Bureaucracy: Dilemmas of the Individual in Public Services. Nova Iorque, Russel Sage Foundation.

MACHADO, Carla, 2004, Crime e Insegurança: Discursos do Medo, Imagens do Outro. Porto, Editorial Notícias.

MIGDAL, Joel S., 1994, “The State in society: an approach to struggles for domination”, em Joel S. Migdal, Atul Kohli e Vivienne Shue (orgs.), State Power and Social Forces: Domination and Transformation in the Third World. Cambridge, Cambridge University Press: 7-36.

MITCHELL, Timothy, 1991, "The limits of the State: beyond statist approaches and their critics", American Political Science Review, 85 (1): 77-96.

NORMANDEAU, André (org.), 1998, Une Police Professionelle de Type Communautaire. Quebeque, Éditions du Méridien.

ROBERT, Philippe, 1999, Le Citoyen, le Crime et l'État. Paris, Droz.

SANTORO, Emilio, 2005, "Modalità punitive e strutture della soggettività: il carcere democratico: una lettura foucaultiana delle nuove politiche penali”, em A. Petrillo (org.), Un Lavoro Disperso e Mutevole: La Cartografia Sociale di Michel Foucault. Avelino, Sellino Editore.

SCOTT, James C., 1998, Seeing like a State: How Certain Schemes to Improve the Human Condition Failed. New Haven, Yale University Press.

SENELlarT, Michel, 2004, "Situation des cours", em Michel Foucault, Sécurité, Territoire, Population: Cours au Collège de France, 1977-1978. Paris: Seuil/Gallimard, 371-411.

SILVERMAN, E. B., e P.E. O'CONNELL, 1998, "Organizational changes and decision making in the New York City Police Department", International Journal of Public Administration, 22 (2): 217-259.

SIMON, Jonathan, 1988, "The ideological effects of actuarial practices", Law and Society Review, 22 (4): 772-800.

—, 2007, Governing through Crime: How the War on Crime Transformed American Democracy and Created a Culture of Fear. Oxford, Oxford University Press.

SONTAG, Susan, 1988, AIDS and its Metaphors. Auflage, Farrar Straus and Giroux.

SPARKS, Richard, 1995, "What are we afraid of? Some current dilemmas of security", Prison Service Journal, 102: 28-34.

THELEN, Tatiana, e Rosie READ, 2007, "Social security and care after socialism: changing notions of need, support and provision", Focaal: European Journal of Anthropology, 50: 3-18.

YOUNG, Jock, 1999, The Exclusive Society: Social Exclusion, Crime and Difference in Late Modernity. Londres, Sage Publications.

WACQUANT, Loïc, 2002, "Scrutinizing the street: poverty, morality, and the pitfalls of urban ethnography”, American Journal of Sociology, 107 (6): 1468-1532. 


\section{WACQUANT, Loïc, 2009, Punishing the Poor: The Neoliberal Government of Social Insecurity. Durham, Duke University Press.}

On the meaning of security: reductions and ambiguities - Manuela Cunha - CRIA-UM, Portugal; IDEMEC/CNRS, França • micunha@ics.uminho.pt • Susana Durão • ICS-UL, Portugal • ssbdurao@gmail.com

Security and insecurity are approached here through an exploratory broad focus that intentionally departs from narrow definitions of the subject. It takes issue with current frameworks that have gradually confined these notions to one of their dimensions and have isolated it from its complex relationships with others. In doing so, they also have abstracted it from other aspects of social life in which it is embedded. Renewing with the wide scope of such notions, which include connotations of stability, predictability, protection, or, on the contrary, vulnerability and precariousness, we examine their reductionist understandings and the ambiguities that surround them. We therefore aim to recover sufficient analytical room to accommodate in such categories aspects related to the provision of security and the production of insecurity at the various levels they may emerge, from ideological notions and cultural perceptions, to social relationships, institutional practices, and the workings of the State and its agents. It is in this framework that we present the contents of this issue.

KEYWORDS: security, perceptions of insecurity, social protection, social vulnerability, notions of risk. 